\title{
Bracing in Clubfoot: What is Different in 2021?
}

\author{
Shobhit Gupta ${ }^{1}$, Anil Agarwal ${ }^{2}$
}

\begin{abstract}
Bracing is an integral and essential part of Ponseti's management of clubfoot. The standard foot abduction brace (FAB) maintains the affected foot in $60-70^{\circ}$ abduction and $10-15^{\circ}$ dorsiflexion while keeping the foot apart at a distance approximately equal to both shoulders' width. Foot abduction brace is recommended to be worn full time for the initial 3-4 months and subsequently night/nap time till 4-5 years of age. Foot abduction brace prevents relapse by continuous stretching of posteromedial soft tissue of the foot and gradually ensuring their stress relaxation. Several designs of FAB are marketed like Denis Browne splint, Steenbeek brace, Mitchell-Ponseti brace, Dobbs brace, etc. The prolonged use of brace required for maintenance of deformity correction is however marred with issues of non-adherence and recurrence. Furthermore, several genetic, socioeconomic, parental, healthcare-related factors affect the overall functionality of the brace. Bracing in clubfoot is an evolving science. There are efforts to achieve better patient outcomes by eliminating these barriers, better brace designs, and following strategic guidelines. Keywords: Adherence, Clubfoot, Compliance, Foot abduction brace, Ponseti technique, Recurrence, Relapse.

Journal of Foot and Ankle Surgery (Asia Pacific) (2021): 10.5005/jp-journals-10040-1172
\end{abstract}

\section{INTRODUCTION}

Ponseti technique is a widely accepted and successful treatment for obtaining correction in clubfoot. The success rate with the technique for initial correction of deformity as reported by Ponseti himself is about $80 \%$ and $92-100 \%$ in various other studies. ${ }^{1,2}$ However, clubfoot deformity has a strong tendency to recur due to presence of retractile tissues. ${ }^{3}$ Recurrence up to 10 years of age and rates as high as $67 \%$ have been reported in the literature. ${ }^{4}$ Thus, the Ponseti technique comprises an aggressive corrective phase involving serial manipulation and casting with or without tenotomy followed by a long-term maintenance phase to prevent recurrence. Bracing plays a key role in maintaining the deformity correction. A brace capable of stretching the foot into abduction and dorsiflexion (foot abduction brace, $F A B$ ) is generally used for this purpose. To prevent recurrence of deformity, FAB has to be worn persistently and for several years. Although the efficiency of FAB to prevent recurrence has been established beyond doubt, the patient's adherence to brace for the prescribed duration remains a potential challenge. ${ }^{5}$

Clubfoot is a disease of masses and the clubfoot program is state-sponsored in several countries. Several of these programs are run in healthcare constrained and limited financial resource settings. A growing child may require several changes of the brace during the maintenance phase and this adds to the overall cost of clubfoot treatment. Therefore, there is an ongoing quest to find an appropriate brace to match contrasting demands of usefulness, comfort, adherence, and cost-effectiveness. The following review briefly discusses the various aspects of brace use in clubfoot, the current brace designs available, the challenges, and future research in this direction.

\section{Original Foot Abduction Brace Used by Ponseti}

The preliminary brace described for use following correction by Ponseti technique was a modified Denis Browne splint. ${ }^{2}$ The original Denis Browne splint (also known as "Hobble splint") was used for achieving clubfoot deformity correction rather than
1,2Department of Pediatric Orthopedics, Chacha Nehru Bal Chikitsalaya, New Delhi, India

Corresponding Author: Anil Agarwal, Department of Pediatric Orthopedics, Chacha Nehru Bal Chikitsalaya, New Delhi, India, Phone: +91 9810290295, e-mail: anilrachna@gmail.com

How to cite this article: Gupta S, Agarwal A. Bracing in Clubfoot: What is Different in 2021? J Foot Ankle Surg (Asia Pacific) 2021;8(3):118-125. Source of support: Nil

Conflict of interest: None

maintenance. It was based on the principle of fixing the two feet with each other in relation to the median plane of the body and thus preventing pivoting. ${ }^{6}$ To achieve the same, the pair of foot pieces were connected by heels. At the connection, the foreparts were twisted to an angle of $20^{\circ}$ in the normal foot and the other foot was turned outwards as far as it was originally inwards. The foot was tied to the splint using a "figure of 8 " bandage (Fig. 1). ${ }^{6} \mathrm{~A}$ child could kick freely in this splint which Denis Browne considered most important for the development of calf muscles and heel. Later, he used open-toed shoes instead of sticking plaster to hold the feet, attached to the bar. $^{7}$

Ponseti and Smoley used this brace in a modified form by using high-top shoes with well-molded heels attached to the Denis Browne bar. ${ }^{1}$ Shoes were attached at $70^{\circ}$ of external rotation and the bar bent $10^{\circ}$ dorsiflexion to keep foot plantar-flexors stretched. The shoes were laced with no curves. The bar ranged in length from 20 to $30 \mathrm{~cm}$ according to the size of the child.

\section{Functions of Foot Abduction Brace}

Clubfoot correction by the Ponseti technique can be explained by "creep and stress relaxation" phenomenon. ${ }^{3}$ During serial manipulation and casting, tendons, ligaments, and soft tissues elongate under a constant load which is described as "creep". After the final cast in maximum abduction and dorsiflexion, FAB creates "stress relaxation" of ligaments which is a decrease in load under continuous elongation. Foot abduction brace helps in continued 

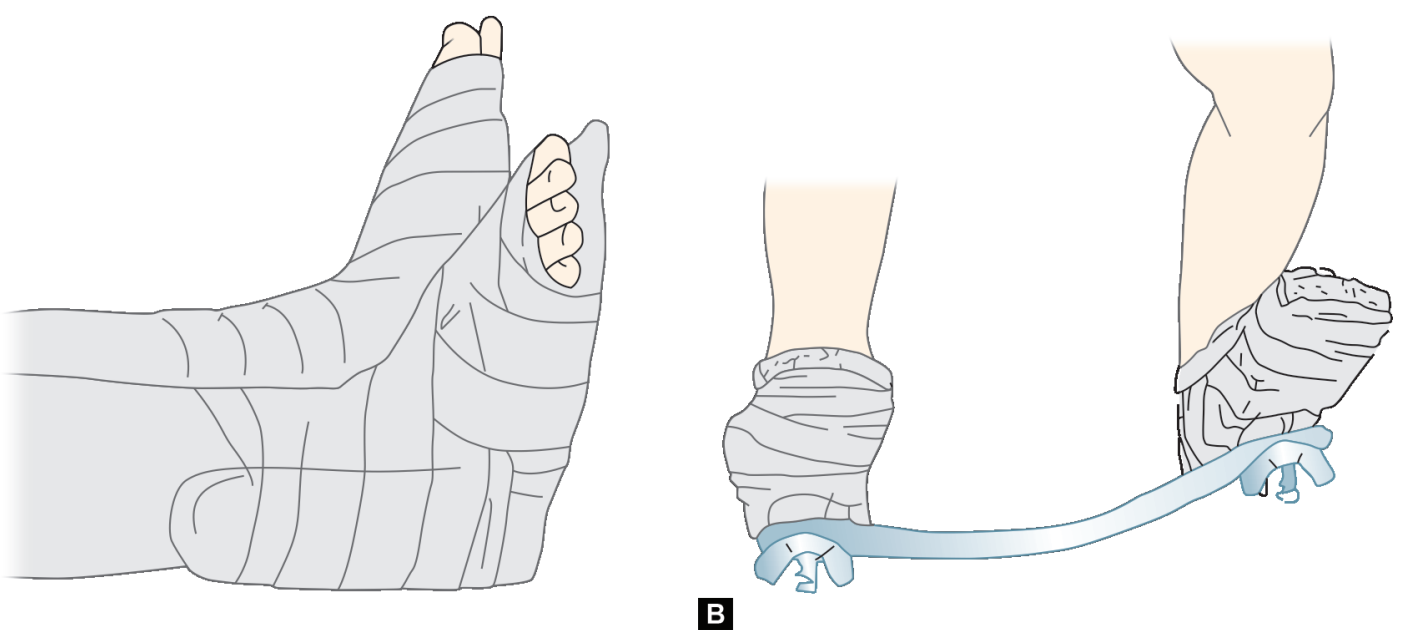

Figs $1 \mathrm{~A}$ and B: Diagrammatic illustration of the splint used by Denis Browne: (A) Hobble splint after application by "figure of 8" bandage; (B) Denis Browne splint with the attached bar

stretching of posteromedial tissue and their development and thus helps in the prevention of recurrence.

Ponseti stated that recurrence in clubfoot is not the result of under correction but it occurred because of the abnormality of the soft tissue of the lower leg, ankle, and foot which had caused the primary congenital deformity. ${ }^{8}$ Since the foot grows almost half of its adult size by 2 years of age, ${ }^{5}$ there are high chances of recurrence of clubfoot deformity in this period. ${ }^{8}$ The importance of brace in the initial few years, therefore, cannot be underestimated.

In Ponseti's study, adherent patients had a recurrence rate of $7 \%$, whereas non-adherent patients had a recurrence rate of $78 \%{ }^{8}$ In several other series, recurrence in brace non-adherent patients is to the tune of $32-88 \%^{9,10}$ compared to $4-22 \%^{9,11}$ in adherent patients. Although the brace type, definition of recurrence, adherence, and bracing protocols is different in various studies, ${ }^{12}$ there is almost a consensus that FAB is mandatory for prevention of recurrence. ${ }^{9,13-15}$

\section{Brace Designs}

In the "Hobble splint" design, Denis Browne explained the reason for attaching both legs to each other. ${ }^{6}$ One foot keeps the other in the abduction and external rotated position. Movements at the hip, knee and ankle are permitted. These movements and activities are necessary for the development of muscles and thus prevent a recurrence. The modified brace has inherent $10-15^{\circ}$ dorsiflexion which also helps in stretching of gastrosoleus tendon. The clubfoot braces most commonly used today employ a similar construct regardless of manufacturer or setup specifications.

However, the bar in FAB makes the routine activities uncomfortable especially for older children and it thus results in non-adherence. To improve adherence, several modifications including removal of the bar (unilateral FAB/orthosis) have been developed and studied at some centers.

\section{Types of BRACES}

\section{Denis Browne Bar and Splint}

Although the original description had different specifications, any brace with a central bar, with the provision of foot attachments in external rotation and dorsiflexion came to be known as Denis
Browne bar. High topped boot/ankle foot orthosis (AFO)/Markell straight last shoes ${ }^{16}$ (http://www.markellshoe.com)/Mitchell clubfoot sandals ${ }^{17}$ (http://www.mdorthopaedics.com) could be attached to the Dennis Browne bar. Several variations and descriptions are therefore found for this splint (Fig. 2).

\section{Steenbeek Brace}

Developed by Michiel Steenbeek and David Okello using easily available local materials and tools, Steenbeek brace is a low cost brace. ${ }^{18}$ It costs $<10$ USD and therefore one of the widely used braces for clubfoot. It is used in many clubfoot programs run in developing countries of Africa and Asia, e.g., Uganda, Ethiopia, Malawi, Zambia, Tanzania, Rwanda, Haiti, Honduras, Paraguay, Laos, Kenya, Nepal, India, and Bangladesh (Fig. 3).

\section{Mitchell Ponseti Brace}

Also known as Ponseti ${ }^{\mathrm{TM}} \mathrm{FAB} .{ }^{17}$ It was developed to provide a softer, comfortable shoe alternative to improve compliance. The shoes are sandal type leather footwear with well molded soft thermoplastic elastomer liner to prevent slippage of the foot (Fig. 4). They have a quick-release mechanism for easy detachment of shoes from the bar which makes it easier to put on and remove them. These shoes are relatively costly.

\section{Dobbs Splint}

It features an articulated bar to allow the child to freely move both legs while maintaining feet in desired dorsiflexion and abduction. ${ }^{19}$ The bar is length adjustable and has a quick-release mechanism in the middle. "Dobbs Bar" usually comes with an adjustable "dorsi assist spring" which allows spring resistance adjustment to keep feet permanently in dorsiflexion. These bars are compatible with Mitchell Ponseti shoes, Markell shoes, or custom-molded solid AFO (Fig. 5). Dobbs bar is promoted for increased parental satisfaction and compliance, however, it is costly.

\section{Modified Braces \\ Flexible Bar}

Kessler replaced Denis Browne bar with polypropylene flexible material which allowed the child to kick freely and plantarflex the ankle without pulling out the heel from the shoes (Fig. 6). ${ }^{20}$ 

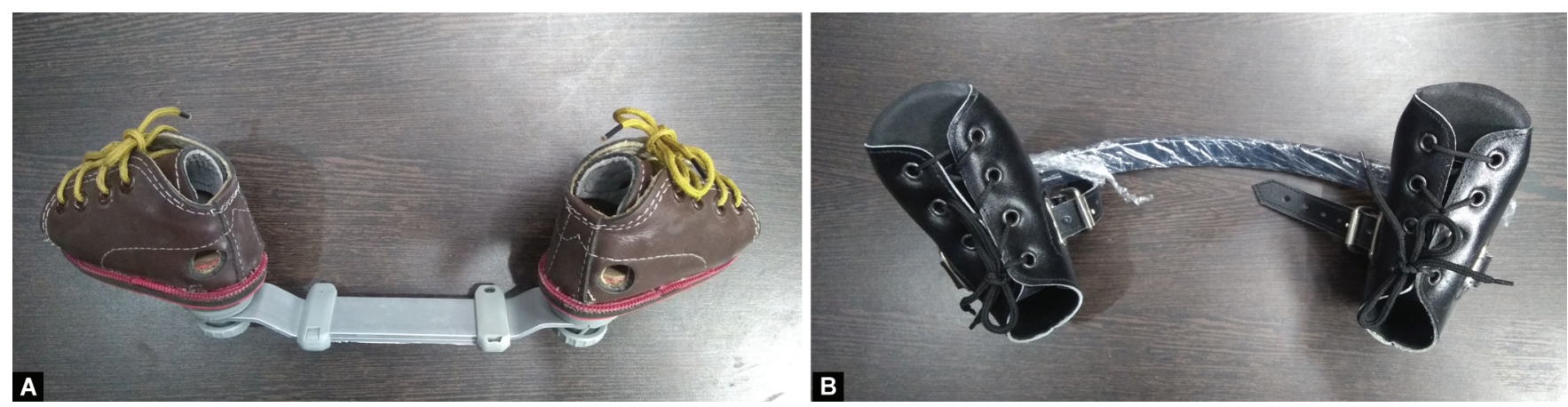

Figs 2A and B: Several variations of Denis Browne splint are used in clinical practice: (A) A modular variety with adjustable bar length and dial; (B) A static variety with fixed configurations

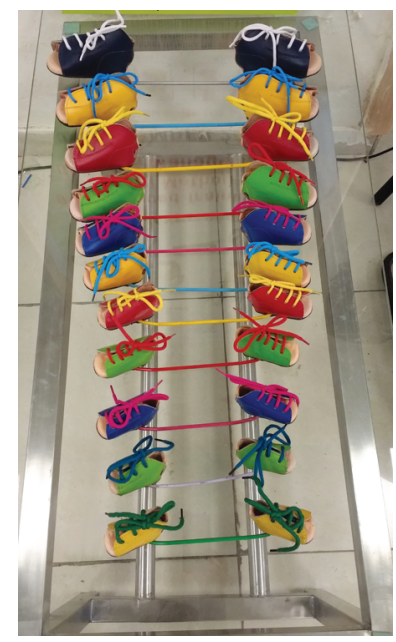

Fig. 3: Steenbeek brace, available in nine sizes (6-14) for foot sizes 6.5 to $14 \mathrm{~cm}$ with standard lengths of the bar from 9.5 to 14 inches

\section{Accordion Hinged Brace}

Abdi et al. used accordion hinged bar instead of a rigid/articulated bar. This allowed unrestricted free leg movements. Both heels could be brought together due to this mechanism (Fig. 7). ${ }^{21}$

\section{D printable Brace}

An open-source 3D printed brace has been developed. It provides independent leg movements while preserving the desired correction. It is made up of hard plastic and needs soft padding to prevent skin complications. ${ }^{22}$

\section{Unilateral Braces}

Several unilateral braces have also been tried for clubfoot. Some of them have been used as primary brace immediately postcorrection. ${ }^{23-26}$ At other times, their use has been endorsed for older children, those having adherence issues with standard $\mathrm{FAB}$, or as follow-on braces after an initial standard bracing. ${ }^{27,28}$

Janicki et al. showed poor results with an ankle-foot orthosis (AFO). There was a high recurrence rate with a conventional AFO when compared to FAB for deformity maintenance in clubfoot. ${ }^{23}$ Solanki et al. modified the AFO using low-temperature thermoplastics and reported better results. ${ }^{24}$ Chen et al. used two different below-knee orthoses for clubfoot to ensure compliance and improved outcome. A nighttime forefoot abduction shoe (FAS) could possibly correct foot adduction and stretch medial structures

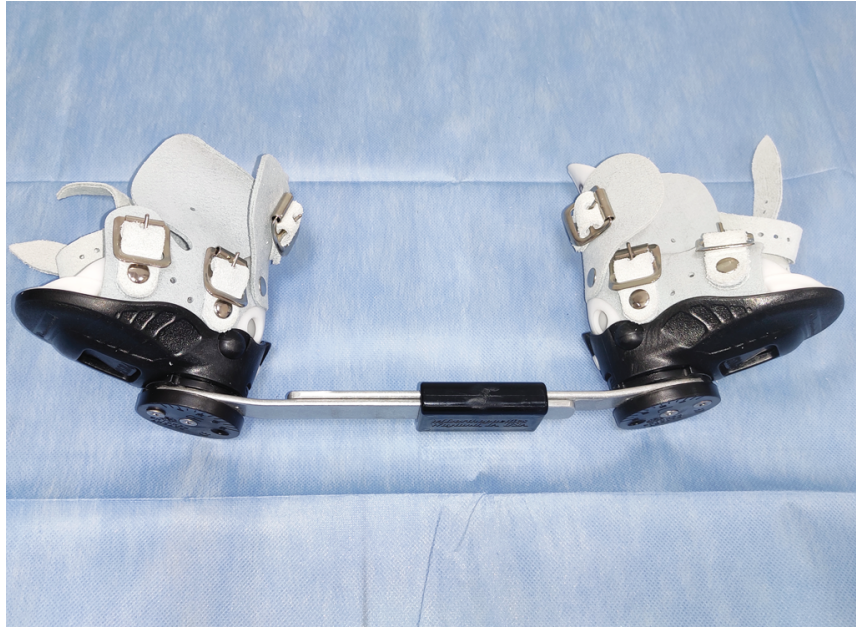

Fig. 4: Mitchell Ponseti brace can be attached with either Ponseti ${ }^{\mathrm{TM}}$ Bar or "Dobbs Bar". Different models are available-(1) Standard, (2) Toe slit, (3) Plantar flexion stop, (4) Plantar flexion stop/Toe slit. Both shoes and Ponseti ${ }^{\mathrm{TM}}$ Bar are available in different sizes

and a daytime orthopedic shoe (OS) responsible for the correction of equinus and varus in a weight-bearing position. ${ }^{29}$ McCartney's device was a dynamic foot brace permitting both inversioneversion and plantar flexion-dorsiflexion. ${ }^{30}$ However, this modular design had a high mechanical failure rate as well. Manousaki et al. utilized two separate braces for different ages. ${ }^{25}$ Both his dynamic knee ankle foot orthosis (KAFO) and AFO worked on the principle of positioning the foot in maximal external rotation relative to the tibia (Fig. 8). Knee ankle foot orthosis was used till 2 years of age and after that AFO was used. George's brace consisted of a shoe, angled metal bar with an in-built dial, and thigh leg straps (Fig. 9). ${ }^{27}$ The brace could abduct, external rotate, and dorsiflex the foot and kept the knee in flexion. Sætersdal et al. used an above-knee orthosis with a hinged ankle joint exerting both dorsal flexion and abduction forces on the foot (Fig. 10). ${ }^{26}$ Berger's lower limb orthosis (LLO) (Fig. 11) was custom-made with resin, carbon, and an inner liner. This custom-made orthosis was made of resin and carbon, has three parts-a circular foot unit, lower leg unit, and inner liner to firmly support the heel. ${ }^{28}$

\section{Bracing Duration}

There is not enough clarity on the ideal bracing duration or precise duration of brace wear to prevent a recurrence. ${ }^{31}$ Recurrences are more common (90\%) in the first 2 years after treatment and subsequently, they decrease with age because of decreased 

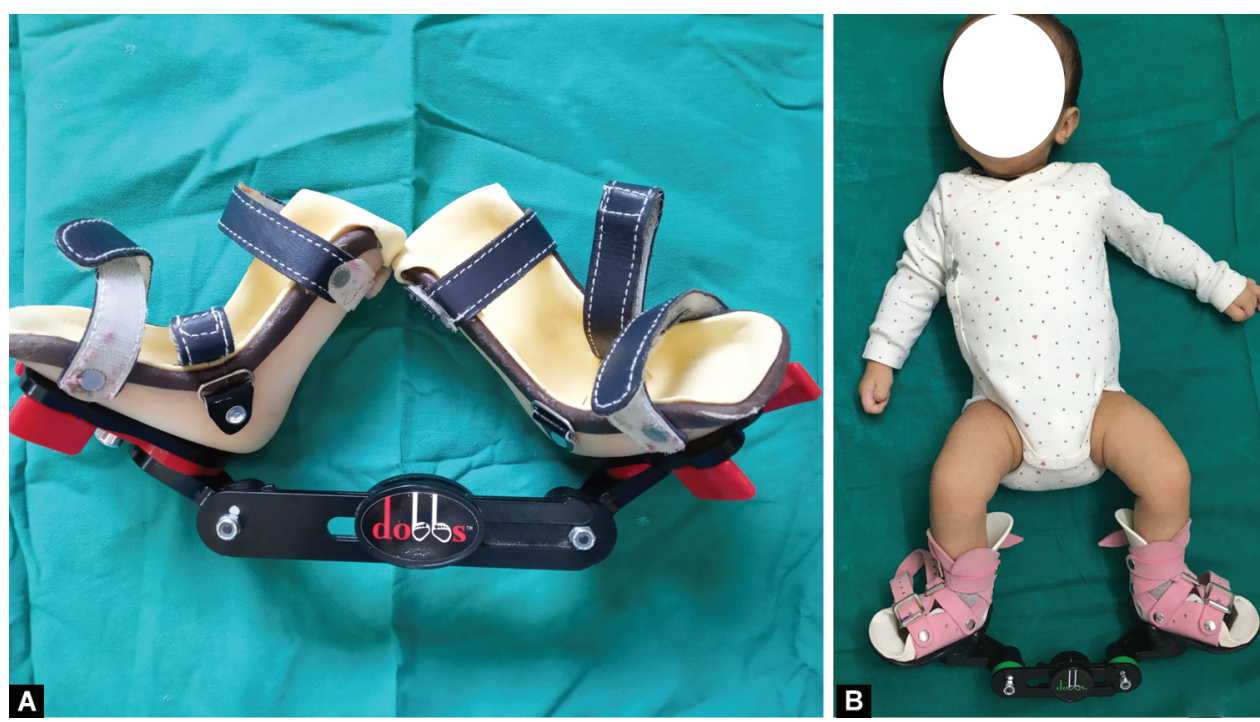

Figs 5A and B: Dobbs Bar, available in adjustable sizes of small (6-9 inches) and regular (9-14 inches): (A) Dobbs bar with AFO type foot piece; (B) Dobbs bar with Mitchell Ponseti type sandals

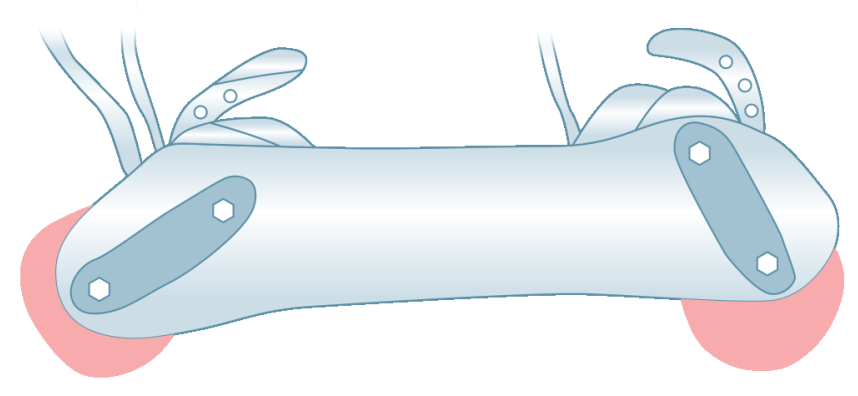

Fig. 6: Brace with flexible bar

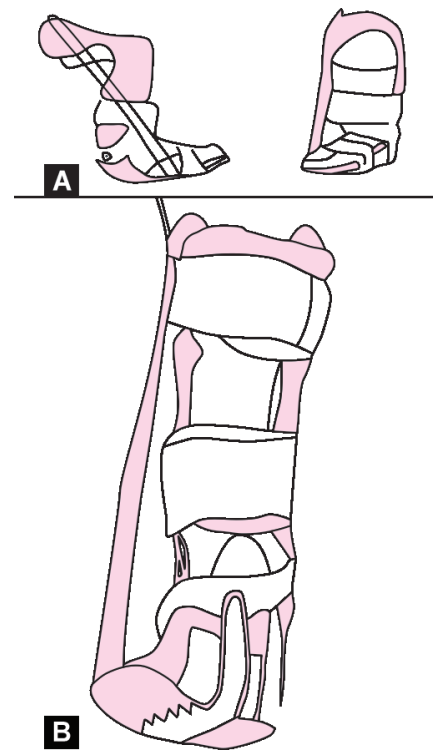

Figs $8 \mathrm{~A}$ and B: Custom-made braces: (A) KAFO and (B) AFO

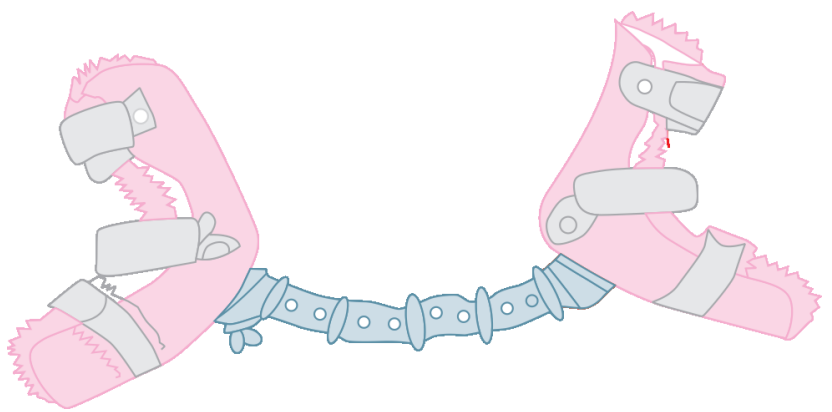

Fig. 7: Accordion hinged brace with no attached rigid bar

growth of foot and are uncommon after the age of 5 years. ${ }^{5}$ Ponseti observed a high recurrence rate (56\%) when the brace was used for 2 years compared to $11 \%$ when it was used up to 4 years of age. ${ }^{9,12,32}$ Several other series have also reported a significant reduction in recurrence rates when brace use was extended till 3-4 years of age. ${ }^{9,32}$ On a survivorship analysis, there was $15 \%$ rise of the probability of relapse between 2 years and 4 years age compared to only $7 \%$ increase between 4 years and 6 years of age which suggested that brace should be worn at least till $4-5$ years of age. ${ }^{4}$

Daily hours of using brace are also variable among different studies. ${ }^{12}$ As a general statement, the brace should be worn for night/nap time for 4-5 years after full-time wear duration for an initial 3-4 months post correction. However, the sleep pattern of every child is different and also it varies according to age. Recommended sleep hours per day are more for younger ones. ${ }^{33} \mathrm{~A}$ recent sensor based study suggested a minimum 8 hours of brace wear per day to prevent a recurrence. ${ }^{34}$

\section{Factors Affecting Adherence and Strategies to Improve it}

Following factors are considered associated with nonadherence: ${ }^{5,14,35}$

- Healthcare providers-Improper training and understanding of protocols/brace working, incomplete correction of deformity before application of brace. 


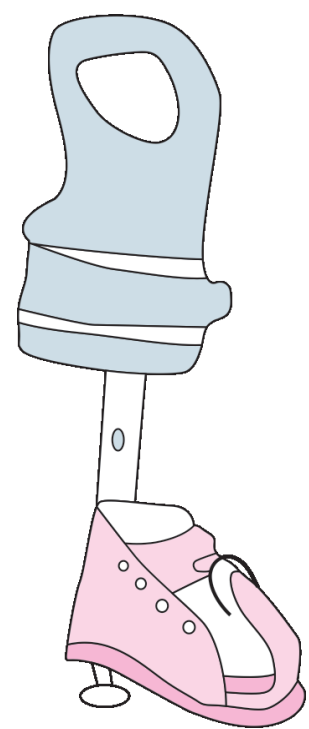

Fig. 9: Unilateral foot abduction orthosis which maintains knee in $90^{\circ}$ flexion. It has an in-built dial mechanism to keep foot abducted in $0^{\circ}$ to $70^{\circ}$ and provide dorsiflexion from $10^{\circ}$ to $15^{\circ}$

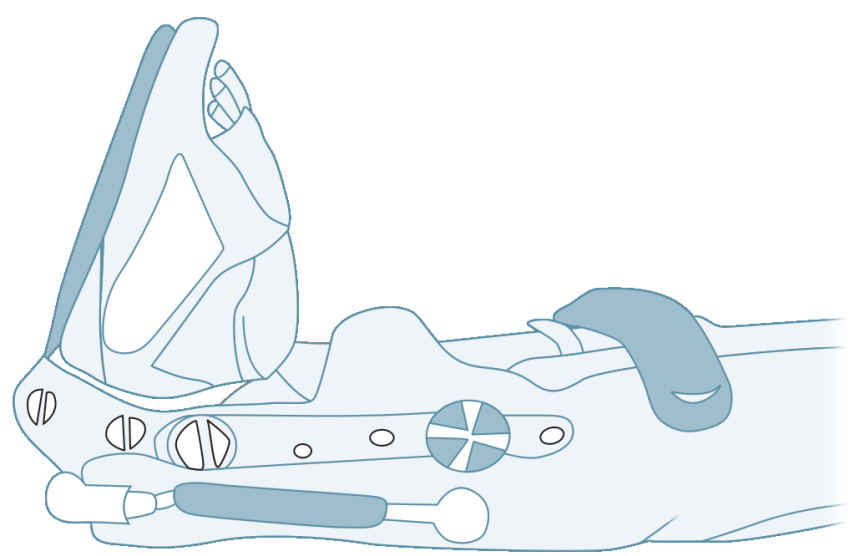

Fig. 11: Lower limb orthosis based on principles of the calcaneusrotation-ring type orthosis and consists of a circular foot unit, a lower leg unit, and an inner liner. It keeps an external rotation of $20^{\circ}$ and allows $5^{\circ}$ plantarflexion to $20^{\circ}$ dorsiflexion

- Healthcare receivers (includes parents) - Lower education, low income, anxiety, psychological, forceful use of brace despite the recurrence of deformity, disability stigma.

- Social and cultural-Poor accessibility of braces, communication gaps, lack of public insurance, unavailability of continuous medical care.

- Brace related-Poor fitting, skin problems, sporadic crying of an infant, sleep disturbance, etc.

To overcome these barriers, the following strategies have been suggested:

- Proper understanding of Ponseti technique and bracing protocols by healthcare providers. They are responsible for explaining the importance of brace adherence to the parents since starting the treatment. At each cast change, parents should be informed about the brace's importance. Parents should be

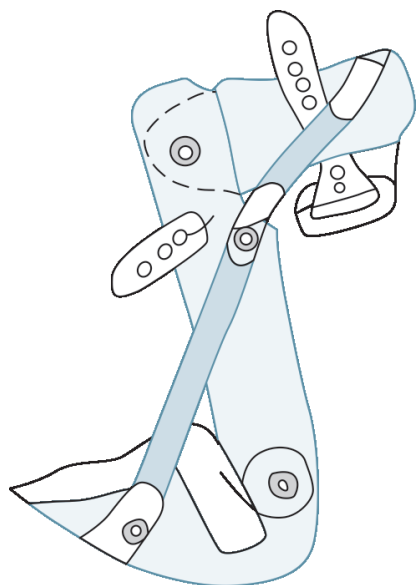

Fig. 10: Custom-made unilateral above knee orthosis with hinged ankle joint

assured that the child may cry for a few initial days of brace application but it is not due to pain.

- Providing written instructions, educational material, Internet sources (videos/authentic websites) to parents. Parents should fully understand the method of brace application before leaving the clinic.

- Complete correction of deformity before brace application and early identification of any relapse.

- Adequate padding of bar/metal pieces to avoid any injury to the child.

- Timely identification of any skin complications and its proper management.

- Availability of adequate stock of proper-sized brace.

- Proper communication and trust between parents and physicians. Resolve any issues related to brace adherence at each visit. A helpline number/easy contact with a physician/ counselor is preferred.

- Habit-forming. Application of brace every time the child naps to make bracing a necessary part of habit related to sleep.

- Promoting child's movements with the brace on through kicking movements of legs.

- Parents should not be criticized for poor adherence, rather they should be encouraged/made partners in treatment to improve adherence to bracing protocol.

- Check for the pattern of shoe wear and tear to ensure adherence as reported by parents.

\section{Challenges with Available Braces}

Despite the availability of many braces, no brace design ensures $100 \%$ adherence or avoids potential complications like sleep disturbance, skin problems (Fig. 12), etc. Since the child has to wear the brace for several years, the main issues with the brace are reported when the child grows older, becomes more mobile (esp. walking) and the deformity appears apparently corrected to parents. Steenbeek brace and other brace using Denis Browne bar are nonarticulated and hinder free kicking movements. ${ }^{3,5}$ This makes the child fussy and parents usually remove the shoes to make the child comfortable. Articulated braces supposedly provide more freedom to the child in movement and may ensure better compliance but their superiority over non-articulated braces in functionality terms is not evidenced. ${ }^{3,5}$ Moreover, they are costly and thus not 


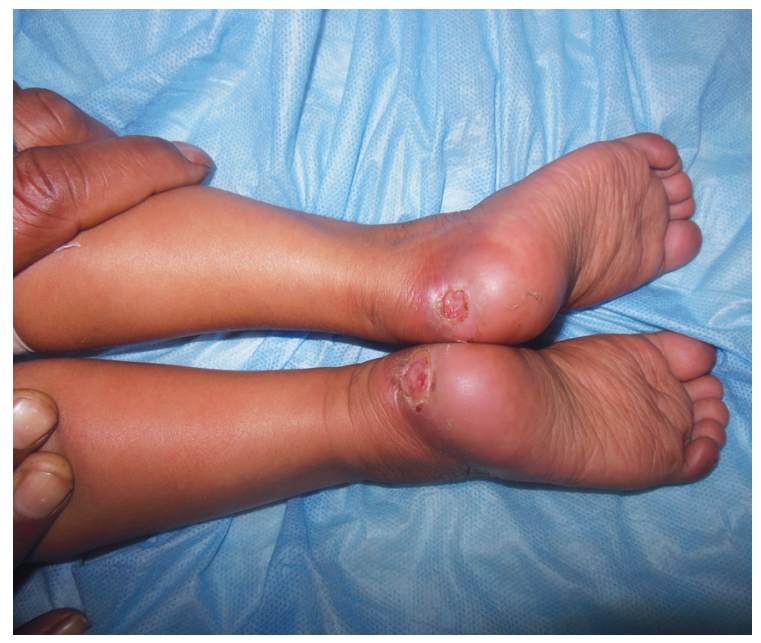

Fig. 12: Bilateral heel ulcers due to imperfect brace application

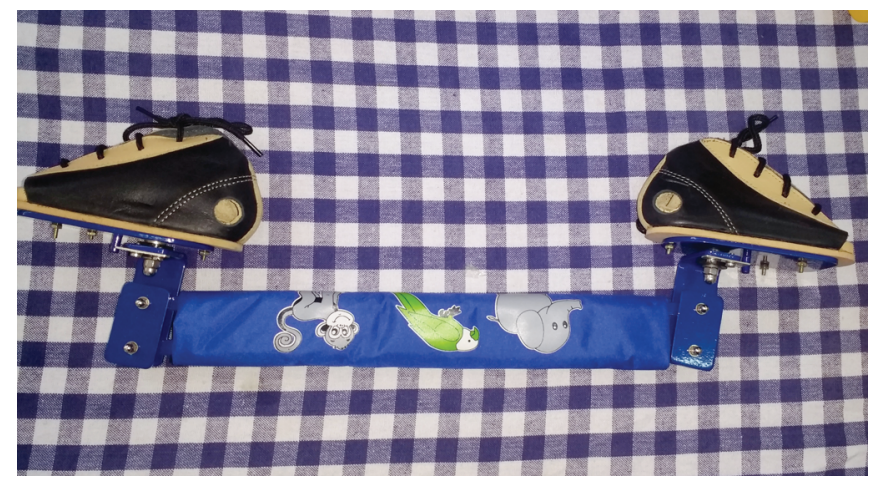

Fig. 14: PADMAPADA® brace with inbuilt pressure sensors for proper monitoring of brace adherence. Hinges allow the child to move legs independently

accessible to all children or suitable for mass programs. ${ }^{31}$ Further, a brace with a quick-release mechanism for easy detachment of shoes from the bar may seem easier to use and potentially increase adherence but it is also prone to technical problems related to the release mechanism. ${ }^{35}$ The unilateral braces although may offer better adherence but are less effective and higher recurrence rates have been reported following their use. ${ }^{24,26,27} \mathrm{~A}$ comparative study reversed its perspective on the use of unilateral limb orthosis in favor of standard FAB on longer follow-up. ${ }^{26}$ Interestingly, there is a certain percentage of children where clubfoot will recur despite adherent bracing, whereas in some correction is maintained in long-term despite poor adherence. ${ }^{35,36}$

An ideal FAB should thus have the following characteristics: ${ }^{37}$

- Universal brace for different sizes of feet.

- Low cost.

- Child safety (non-toxic non-allergic material, devoid of heat radiation).

- User-friendly (ergonomic design, durable and lightweight, able to walk with braces).

- Skin-friendly (comfortable, well-padded linings and straps, smooth non-traumatic hardware).

- Detachable shoes.

- Adjustable bar length.

- Compliance monitoring sensors.
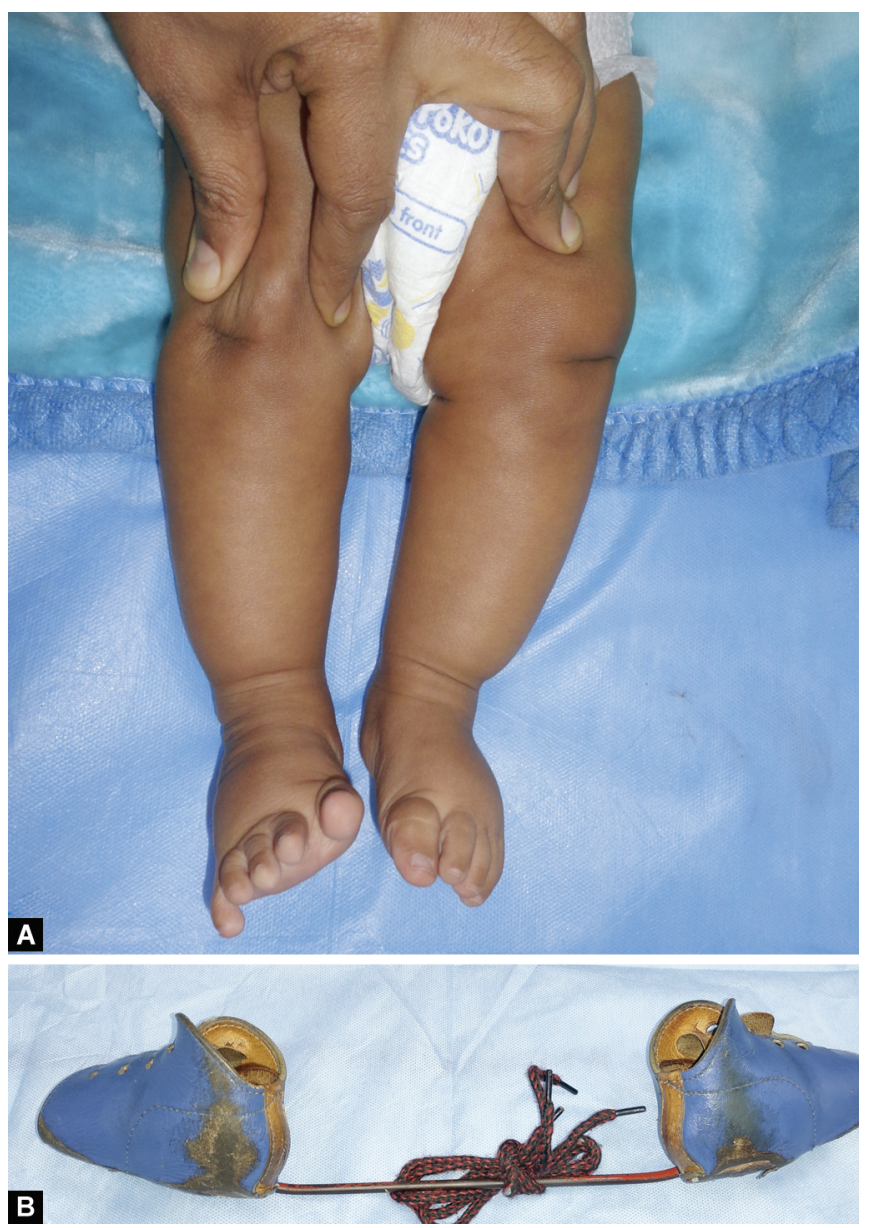

Figs $13 \mathrm{~A}$ and $\mathrm{B}$ : (A) Hourglass constriction sign in early brace period; (B) Orthotic wear sign indicates good adherence with a brace in late brace period

- Easy accessibility to all children all over the world/applicability in low-cost mass programs.

\section{Way Forward}

Clubfoot is a disease of masses. There is still limited accessibility to the braces where it is required most. ${ }^{38}$ Locally made braces can overcome the barrier of accessibility. The Steenbeek brace made of locally available material and low cost is one such step in this direction. Further, there are local and social barriers to $F A B$ adherence. Non-profit organizations may play an important role in this factor by increasing awareness, educating, and ensuring accessibility of $F A B$ to all children without delay, by widespread recycling of braces and establishing local production units..$^{35,38}$

Several key researches have helped in our understanding of FAB use in clubfoot. Braces may need customization according to the ethnicity of children and socioeconomic factors. ${ }^{39}$ Accurate objective assessment of adherence rather than merely relying on parent's statement, either by clinical methods like "leg hourglass sign" (in "early" brace wear period) (Fig. 13A) and orthotic wear sign (for "late" brace wear period) ${ }^{40}$ (Fig. 13B) or by advanced monitoring systems (pressure/thermal sensors, real-time sensors) like PADMAPADA@ brace (Fig. 14) may play a crucial role in preventing recurrences. ${ }^{9,33,41,42}$ Newer unilateral braces are being marketed 


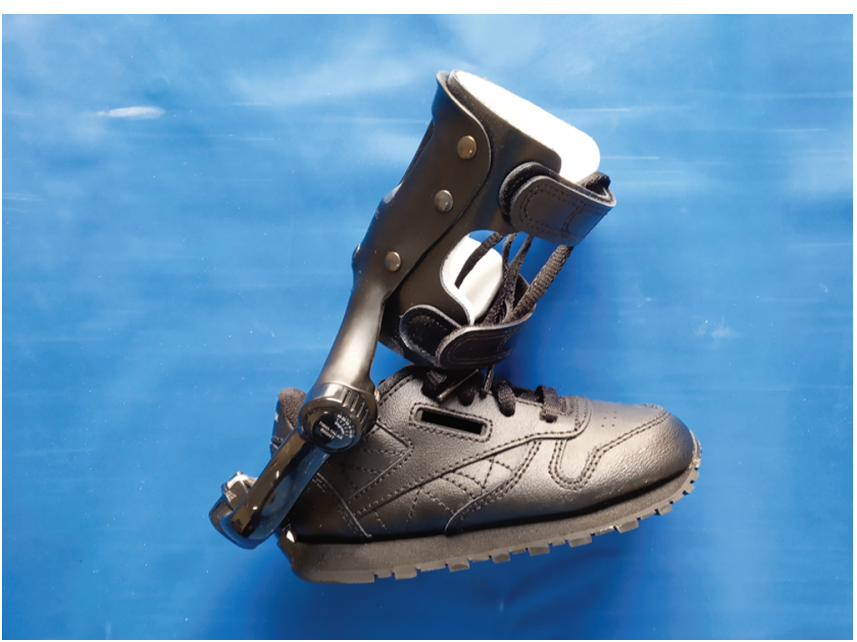

Fig. 15: A below-knee unilateral brace based on abduction dorsiflexion mechanism (ADM). It is now available with improved designs (ambulatory and non-ambulatory ADM). Two spring-loaded mechanisms keep the foot stretched in the desired position while the child is asleep but allows movements of $5^{\circ}$ of inversion to $30^{\circ}$ eversion, and $45^{\circ}$ of plantarflexion to $30^{\circ}$ of dorsiflexion

(Fig. 15) and boast to work on similar principles of standard FAB with bar. ${ }^{28}$ These may have better patient acceptance and compliance. Surrogate bio-models are now available which will help to better understand the functionality and dynamicity of brace. ${ }^{32}$ Previously, patient adherence and recurrence were the chief parameters to make comparison between braces. Quantitative methods to test the efficacy of bracing are now available. ${ }^{43,44}$

Daily bracing duration and the total duration of bracing have always been an active area of research. Knowing the adequate dose of brace will be cost-effective, provide more freedom for the child, and decrease the complications associated with longer duration of brace wear. Several studies have suggested that the brace wear should be tailored to the severity of assessment. ${ }^{45}$ Some children may need more casts and longer bracing durations while a shorter bracing period may be effective for others. ${ }^{45}$ Contrarily, it has been shown that a longer initial bracing period in corrected idiopathic clubfoot and longer night brace duration results in a reduction of the number of recurrences and better functional score. ${ }^{45,46}$ Newer sensor-based braces are contributing a great deal in finding the gaps between patient-reported and actual brace wear times. Results of the must-awaited prospective study "The Clubfoot Foot Abduction Brace Length of Treatment Study (FAB24)" may enlighten and provide data on the minimum duration of brace wear required to prevent relapse. ${ }^{31}$ Attempts are also underway to possibly get rid of brace altogether through extensive exercise programs ${ }^{47}$ or an early tendon transfer surgery. ${ }^{48}$

Whatever be the advances, it also becomes essential that future researches have robust study designs and methodology. There should be uniformity in the definition of deformity correction, recurrence, non-adherence, and bracing protocols to compare the results with various types of $F A B$.

\section{Conclusion}

Although the Ponseti technique has revolutionized clubfoot treatment, the deformity correction needs maintenance for prolonged periods. The FAB is one of the reliable methods for achieving the same. Since the brace needs to be used for several years, potential issues such as patient adherence and recurrence are major challenges in clubfoot treatment.

Till further evidence is available regarding the shorter duration of bracing and the efficacy of newer designs, it is essential to stick to established bracing protocols and standard FABs to provide maximum benefit to patients. Strengthening health provider's training, parental education and counseling, eliminating social barriers, and improving accessibility of affordable braces will help achieve the desired goal of minimum disability due to clubfoot.

\section{References}

1. Ponseti IV, Smoley EN. The classic: congenital club foot: the results of treatment. 1963. Clin Orthop Relat Res 2009;467(5):1133-1145. DOI: 10.1007/s11999-009-0720-2.

2. Laaveg SJ, Ponseti IV. Long-term results of treatment of congenital club foot. J Bone Joint Surg Am 1980;62(1):23-31. DOI: 10.2106/00004623198062010-00004.

3. Zhao D, Liu J, Zhao L, et al. Relapse of clubfoot after treatment with the Ponseti method and the function of the foot abduction orthosis. Clin Orthop Surg 2014;6(3):245-252. DOI: 10.4055/cios.2014.6.3.245.

4. Thomas HM, Sangiorgio SN, Ebramzadeh E, et al. Relapse rates in patients with clubfoot treated using the ponseti method increase with time: a systematic review. JBJS Rev 2019;7(5):e6. DOI: 10.2106/ JBJS.RVW.18.00124.

5. Zionts LE, Dietz FR. Bracing following correction of idiopathic clubfoot using the Ponseti method. J Am Acad Orthop Surg 2010;18(8):486493. DOI: $10.5435 / 00124635-201008000-00005$.

6. BrowneD. Congenital talipes equino-varus. Br Med J 1931;2(3693):696699. DOI: 10.1136/bmj.2.3693.696.

7. Browne D. Talipes equino varus. Postgrad Med J 1937;13(144):349-362. DOI: 10.1136/pgmj.13.144.349.

8. Ponseti IV. Relapsing clubfoot: causes, prevention, and treatment. lowa Orthop J 2002;22:55-56.

9. Morcuende JA, Dolan LA, Dietz FR, et al. Radical reduction in the rate of extensive corrective surgery for clubfoot using the Ponseti method. Pediatrics 2004;113(2):376-380. DOI: 10.1542/peds.113.2.376.

10. Göksan SB, Bilgili F, Eren I, et al. Factors affecting adherence with foot abduction orthosis following Ponseti method. Acta Orthop Traumatol Turc 2015;49(6):620-626. DOI: 10.3944/AOTT.2015.14.0348.

11. Goldstein RY, Seehausen DA, Chu A, et al. Predicting the need for surgical intervention in patients with idiopathic clubfoot. J Pediatr Orthop 2015;35(4):395-402. DOI: 10.1097/BPO.0000000000000282.

12. Zhao D, Li H, Zhao L, et al. Results of clubfoot management using the Ponseti method: do the details matter? a systematic review. Clin Orthop Relat Res 2014;472(4):1329-1336. DOI: 10.1007/s11999-0143463-7.

13. Haft GF, Walker CG, Crawford HA. Early clubfoot recurrence after use of the Ponseti method in a New Zealand population. J Bone Joint Surg Am 2007;89(3):487-493. DOI: 10.2106/JBJS.F.00169.

14. Avilucea FR, Szalay EA, Bosch PP, et al. Effect of cultural factors on outcome of Ponseti treatment of clubfeet in rural America. J Bone Joint Surg Am 2009;91(3):530-540. DOI: 10.2106/JBJS.H.00580.

15. Kuzma AL, Talwalkar VR, Muchow RD, et al. Brace yourselves: outcomes of ponseti casting and foot abduction orthosis bracing in idiopathic congenital talipes equinovarus. J Pediatr Orthop 2020;40(1):e25-e29. DOI: 10.1097/BPO.0000000000001380.

16. Markell shoe [internet]. New York: M.J. MARKELL SHOE CO.; [cited 2020 Oct 25] Available from: https://www.markellshoe.com/tarsochildrens-corrective-shoes.html.

17. MD Orthopaedics [internet]. lowa: MD Orthopaedics, Inc.; [cited 2020 Oct 25] Available from: https://www.mdorthopaedics.com/orderinginformation/.

18. Steenbeek M, Davic OC. Steenbeek brace for clubfoot [internet]. 2nd ed., [cited 2020 Oct 25], Seattle: Global HELP; 2009 https://global-help. org/products/steenbeek_brace_for_clubfoot/. 
19. Dobbs brace [internet]. Missouri: D-Bar Enterprises LLC, [cited 2020 Oct 25] Available from: https://www.dobbsbrace.com/products.

20. Kessler J. A new flexible brace used in the Ponseti treatment of talipes equinovarus. J Pediatr Orthop B 2008;17(5):247-250. DOI: 10.1097/ BPB.0b013e32830cc3e5.

21. Abdi R, Hajzargarbashi R, Baghdadi T, et al. Effect of a modified dynamic accordion hinge Denis Browne brace on the success rate of the Ponseti method in idiopathic clubfoot: a preliminary study. J Pediatr Orthop B 2017;26(2):112-115. DOI: 10.1097/ BPB. 0000000000000357.

22. Savonen B, Gershenson J, Bow JK, et al. Open-source threedimensional printable infant clubfoot brace. J Prosthet Orthot 2020;32(2):49-58. DOI: 10.1097/JPO.0000000000000257.

23. Janicki JA, Wright JG, Weir S, et al. A comparison of ankle foot orthoses with foot abduction orthoses to prevent recurrence following correction of idiopathic clubfoot by the Ponseti method. J Bone Joint Surg Br 2011;93(5):700-704. DOI: 10.1302/0301-620X.93B5.24883.

24. Solanki PV, Sheth BA, Poduval M, et al. Effectiveness of modified ankle foot orthosis of low-temperature thermoplastics in idiopathic congenital talipes equino varus. J Pediatr Orthop B 2010;19(4):353360. DOI: 10.1097/BPB.0b013e3283387d16.

25. Manousaki E, Czuba T, Hägglund G, et al. Evaluation of gait, relapse and compliance in clubfoot treatment with custom-made orthoses. Gait Posture 2016;50:8-13. DOI: 10.1016/j.gaitpost.2016.08.005.

26. Sætersdal C, Fevang JM, Engesæter LB. Inferior results with unilateral compared with bilateral brace in Ponseti-treated clubfeet. J Child Orthop 2017;11(3):216-222. DOI: 10.1302/1863-2548.11.160279.

27. George HL, Unnikrishnan PN, Garg NK, et al. Unilateral foot abduction orthosis: is it a substitute for Denis Browne boots following Ponseti technique? J Pediatr Orthop B 2011;20(1):22-25. DOI: 10.1097/ BPB.0b013e32833fb8a5.

28. Berger N, Lewens $D$, Salzmann M, et al. Is unilateral lower leg orthosis with a circular foot unit in the treatment of idiopathic clubfeet a reasonable bracing alternative in the Ponseti method? Five-year results of a supraregional paediatric-orthopaedic centre. BMC Musculoskelet Disord 2018;19(1):229. DOI: 10.1186/s12891-018-2160-1.

29. Chen W, Pu F, Yang Y, et al. Correcting congenital talipes equinovarus in children using three different corrective methods: a consort study. Medicine (Baltimore) 2015;94(28):e1004. DOI: 10.1097/ MD.0000000000001004.

30. McCartney S, Turner S, Davies K, et al. A new unilateral abduction orthosis for Ponseti-treated clubfoot: a cohort study to assess compliance. Prosthet Orthot Int 2019;43(3):325-330. DOI: 10.1177/0309364618814866.

31. Dobbs MB, Frick SL, Mosca VS, et al. Design and descriptive data of the randomized clubfoot foot abduction brace length of treatment study (FAB24). J Pediatr Orthop B 2017;26(2):101-107. DOI: 10.1097/ BPB.0000000000000387.

32. Dimeo AJSr, Lalush DS, Grant E, et al. Development of a surrogate biomodel for the investigation of clubfoot bracing. J Pediatr Orthop 2012;32(7):e47-e52. DOI: 10.1097/BPO.0b013e3182571656.

33. Richards BS, Faulks S, Felton $\mathrm{K}$, et al. Objective measurement of brace wear in successfully Ponseti-treated clubfeet: pattern of decreasing use in the first 2 years. J Am Acad Orthop Surg 2020;28(9):383-387. DOI: 10.5435/JAAOS-D-19-00163.

34. Sangiorgio SN, Ho NC, Morgan RD, et al. The objective measurement of brace-use adherence in the treatment of idiopathic clubfoot. J Bone Joint Surg Am 2016;98(19):1598-1605. DOI: 10.2106/JBJS.16.00170.

35. Alves C. Bracing in clubfoot: do we know enough? J Child Orthop 2019;13(3):258-264. DOI: 10.1302/1863-2548.13.190069.

36. Bor N, Coplan JA, Herzenberg JE. Ponseti treatment for idiopathic clubfoot: minimum 5-year follow up. Clin Orthop Relat Res 2009;467(5):1263-1270. DOI: 10.1007/s11999-008-0683-8.

37. Mohamaddan S, Rasit AH, Dawal SZM. Design of mechanical bracing device for clubfoot treatment. J Telecom Electro Comp Enginee 2018;10:91-95.

38. Nogueira MP, Fox M, Miller K, et al. The Ponseti method of treatment for clubfoot in Brazil: barriers to bracing compliance. lowa Orthop J 2013;33:161-166.

39. Agarwal A, Agrawal N, Dubey A, et al. Is the same brace fit for all? The length of abduction bar in Steenbeek foot abduction brace for Indian children-a pilot study. J Clin Orthop Trauma 2019;10(1):209-212. DOI: 10.1016/j.jcot.2017.10.014.

40. Agarwal A, Gupta S. Letter to the editor. Brace compliance in clubfoot: clinical signs. J Clin Orthop Trauma. 2020;11:344-346.

41. Morgenstein A, Davis R, Talwalkar V, et al. A randomized clinical trial comparing reported and measured wear rates in clubfoot bracing using a novel pressure sensor. J Pediatr Orthop 2015;35(2):185-191. DOI: 10.1097/BPO.0000000000000205.

42. Department of Science \& Technology [internet]. New Delhi: Government of India; [updated 2019 Dec 11; cited 2020 Oct 25]. Available from: https://dst.gov.in/brace-assist-children-clubfootpromises-freedom-disability.

43. Agarwal A, Kumar A, Shaharyar A, et al. The dynamicity of Steenbeek foot abduction brace for clubfoot in dorsiflexion and pronation: a pilot study. Foot Ankle Spec 2016;9(5):394-399. DOI: 10.1177/1938640016640894.

44. Agarwal A, Kumar A, Mishra M. The foot abduction characteristics following Steenbeek foot abduction brace. J Orthop Surg (Hong Kong) 2017;25(1):2309499016684085 10.1177/2309499016684085.

45. Hemo Y, Gigi R, Wientroub S. Delayed ossification and abnormal development of tarsal bones in idiopathic clubfoot: should it affect bracing protocol when using the Ponseti method? J Child Orthop 2019;13(3):265-270. DOI: 10.1302/1863-2548.13.190080.

46. Shabtai L, Segev E, Yavor A, et al. Prolonged use of foot abduction brace reduces the rate of surgery in Ponseti-treated idiopathic club feet. J Child Orthop 2015;9(3):177-182. DOI: 10.1007/s11832-0150663-y.

47. Sheta RA, El-Sayed M. Is the Denis Browne splint a myth? A longterm prospective cohort study in clubfoot management using Denis Browne splint versus daily exercise protocol. J Foot Ankle Surg 2020;59(2):314-322. DOI: 10.1053/j.jfas.2019.08.026.

48. Gintautienè J, Čekanauskas E, Barauskas V, et al. Comparison of the Ponseti method versus early tibialis anterior tendon transfer for idiopathic clubfoot: a prospective randomized study. Medicina (Kaunas) 2016;52(3):163-170. DOI: 10.1016/j.medici.2016.04.004. 